\title{
Chính sách hỗ trợ doanh nghiệp đổi mới
}

\author{
Phạm Thế Dũng ${ }^{1, *}$, Nguyễn Đình Đức ${ }^{2}$ \\ ${ }^{1}$ Bộ Khoa học và Công nghệ, 113 Trần Duy Hung, Hà Nội, Việt Nam \\ ${ }^{2}$ Đại học Quốc gia Hà Nội, 144 Xuân Thủy, Cầu Giấy, Hà Nội, Việt Nam \\ Nhận ngày 12 tháng 7 năm 2017 \\ Chỉnh sửa ngày 8 tháng 9 năm 2017; Chấp nhận đăng ngày 28 tháng 9 năm 2017
}

\begin{abstract}
Tóm tắt: Đổi mới trong doanh nghiệp đóng vai trò hết sức quan trọng trong việc tạo ra sản phẩm mới, nâng cao năng suất lao động, chất lượng sản phẩm, sử dụng hợp lý, tiết kiệm nguyên liệu, tăng khả năng cạnh tranh, mở rộng thị trường, bảo vệ môi trường, cải thiện điều kiện sống, hạn chế ảnh hưởng của thiên nhiên đến sản xuất và đời sống, đặc biệt trong giai đoạn nước ta đang tiến hành công nghiệp hóa, hiện đại hóa, trong điều kiện kinh tế thị trường và hội nhập quốc tế. Vì vậy, cần phải xây dựng chính sách hỗ trợ doanh nghiệp đổi mới như thế nào cho phù hợp nhằm đáp ứng kịp thời các yêu cầu hội nhập cũng như tạo môi trường pháp lý thuận lợi thúc đẩy doanh nghiệp đồi mới.
\end{abstract}

Tù khóa: Đổi mới trong doanh nghiệp.

\section{Khái niệm đổi mới}

Đổi mới (Innovation) ở đây được hiểu là đổi mới sáng tạo không phải là một hoạt động đơn lẻ và độc lập mà được hiểu như là một hệ thống đa chiều của các yếu tố, quá trình và tác nhân tương tác. Doanh nhân và doanh nghiệp đổi mới là nhân tố chính trong việc truyền tải tri thức và thương mại hóa các sản phẩm, dịch vụ và quy trình. Đổi mới không chỉ là một quá trình tuyến tính một chiều từ nghiên cứu tới các doanh nghiệp và sau đó đưa ra thị trường. Trong thực tế đổi mới là phi tuyến tính và ngày càng là một hoạt động diễn ra trên toàn cầu, đa ngành, đa lĩnh vực và có tương tác với nhau. Đổi mới thành công dựa vào nhiều hoạt động phi kỹ thuật như xây dựng cơ cấu tổ chức, đào

\footnotetext{
*Tác giả liên hệ. ĐT.: 84-913570558.

Email: dungpthe@gmail.com

https://doi.org/10.25073/2588-1116/vnupam.4077
}

tạo, tài chính, tiếp thị, quan hệ khách hàng... Doanh nghiệp ngày nay thực hiện đổi mới, hiếm khi chỉ sử dụng nguồn lực nội bộ của mình. Đổi mới là quá trình trong đó các doanh nghiệp tương tác với môi trường bên ngoài. Họ có thể tận dụng từ các trường đại học vấn đề sở hữu trí tuệ và nguồn nhân lực trình độ cao, tận dụng các nguồn lực tài chính của nhà đầu tư, các kỹ năng của các công ty khác, chuyên gia tư vấn, các nhà cung cấp và thậm chí cả nguồn phát triển sản phẩm từ khách hàng. Đổi mới xảy ra trong bối cảnh của một hệ sinh thái đổi mới, một hệ thống được làm nên bởi nhiều cá nhân, tổ chức tham gia, kết nối và liên kết giữa các khách hàng, nhà cung cấp chính phủ, giáo dục, nghiên cứu, và các ngành kinh tế khác. Đổi mới có nhiều khái niệm hay định nghĩa khác nhau, nhưng tóm lại bản chất của đổi mới là thâm dụng tri thức vào sản phẩm và dịch vụ đáp ứng nhu cầu của người tiêu dùng (thị trường), một số khái niệm cụ thể như là: 
1.1. Theo Schumpeter, Lý thuyết phát triển kinh tế: Đổi mới là "việc ứng dụng một cái gì đó mới trong thương mại hoặc công nghiệp, một sản phẩm, quy trình hoặc một phương thức sản xuất; một thị trường hoặc nguồn cung cấp mới; một hình thức kinh doanh mới, hoặc tổ chức tài chính mới” [1].

1.2. European Commission 2004 (Ủy ban Châu Âu): Đổi mới - là sự kết hợp của phát minh, sáng chế và khả năng làm chủ để giúp cho ngành công nghiệp tăng trưởng, hình thành giá trị mới và tạo ra nhiều việc làm.

1.3. Sổ tay hướng dẫn OSLO - 2005 của $O E C D$ : Đổi mới là quá trình thực hiện một sản phẩm (hàng hóa hay dịch vụ) hay quy trình, một phương thức tiếp thị, hoặc một phương pháp tổ chức trong hoạt động thực tiễn kinh doanh, tổ chức làm hoặc các quan hệ đối ngoại mới hoặc được cải tiến đáng kể [2].

1.4. Theo Luật Khoa học và Công nghệ Việt Nam 2013, Đổi mói sáng tạo (innovation) là việc tạo ra, ứng dụng thành tựu, giải pháp kỹ thuật, công nghệ, giải pháp quản lý để nâng cao hiệu quả phát triển kinh tế - xã hội, nâng cao năng suất, chất lượng, giá trị gia tăng của sản phẩm, hàng hóa [3].

\section{Hoạt động đổi mới và các loại hình đổi mới chính}

2.1. Hoạt động đổi mới: Là tất cả các bước về mặt khoa học, công nghệ, tổ chức, tài chính và thương mại mà thực sự hoặc có xu hướng dẫn tới các hoạt động đổi mới. Một số hoạt động đổi mới mà tự bản thân nó đã mang tính đổi mới, một số khác không phải là các hoạt động có tính mới nhưng lại cần thiết cho quá trình đổi mới, cũng bao hàm cả nghiên cứu và triển khai không liên quan trực tiếp đến sự phát triển của một hoạt động đổi mới cụ thể [2].

\subsection{Các loại hình đổi mới chính:}

Đổi mới bao gồm bốn loại hình sau: đổi mới sản phẩm, đổi mới quy trình, đổi mới tiếp thị và đổi mới về tổ chức [2]:
- Đổi mới sản phẩm là đưa ra một sản phẩm mới hay dịch vụ mới hoặc được cải tiến đáng kể về các đặc tính và tiện ích mong đợi. Đối với sản phẩm bao gồm những cải tiến đáng kể về các đặc tính kỹ thuật, các thành phần, nguyên liệu, phần mềm kèm theo, độ thân thiện với người dùng hay những đặc tính chức năng khác;

- Đổi mới quy trình là thực hiện một phương thức sản xuất hay phân phối mới hoặc được cải tiến đáng kể. Đổi mới quy trình bao gồm những thay đổi đáng kể về kỹ thuật, thiết bị và/hoặc phần mềm;

- Đổi mói tiếp thị là việc thực hiện một phương pháp tiếp thị mới liên quan đến những thay đổi đáng kể về thiết kế sản phẩm hay đóng gói, sắp đặt sản phẩm, quảng cáo sản phẩm hoặc định giá sản phẩm;

- Đổi mới về tổ chức là việc thực hiện một phương pháp tổ chức mới trong hoạt động kinh doanh, sắp xếp nơi làm việc hay các quan hệ đối ngoại của công ty.

\section{Các yếu tố tác động đến đổi mới của doanh nghiệp}

Có hai loại yếu tố tác động đến đổi mới của doanh nghiệp đó là trực tiếp và gián tiếp, trong đó có bốn yếu tố tác động trực tiếp và bốn yếu tố tác động gián tiếp (môi trường).

Bảng 1. Các yếu tố tác động đến đổi mới của doanh nghiệp

\begin{tabular}{ll}
\hline TT & Yếu tố tác động \\
\hline I. & Tác động trực tiếp \\
1.1. & Các yếu tồ đầu vào đổi mới \\
1.2. & Thực hiện/triển khai quá trình đổi mới \\
1.3. & Yếu tố đầu ra \\
1.4. & Yếu tố tác động kinh tế \\
II. & Tác động gián tiếp \\
2.1 & Điều kiện kinh tế vĩ mô \\
2.2 & Cơ sở hạ tầng đổi mới \\
2.3 & Nhận thức của quốc gia \\
2.4 & Môi trường chính sách công \\
\hline
\end{tabular}




\subsection{Các yếu tố tác động trục tiếp}

Các yếu tố tác động trực tiếp bao gồm: đầu vào đổi mới; (thực hiện/ triển khai) quá trình đổi mới; đầu ra đổi mới và tác động kinh tế [4]:

- Các yếu tố đầu vào đổi mới nhu: nghiên cứu triển khai, nguồn nhân lực trình độ cao, vốn, sáng chế và các ấn phẩm khoa học

+ Nghiên cứu và triển khai: kinh phí, sở hữu trí tuệ, các ấn phẩm khoa học.

+ Nhân lực: nguồn nhân lực, giáo dục, năng lực, kinh nghiệm. Tính linh hoạt của lực lượng lao động là một yếu tố đầu vào quan trọng.

+ Vốn: tiếp cận tài chính, đặc biệt là rủi ro và vốn kinh doanh.

+ Mạng lưới: cộng đồng tri thức, mối liên kết, hợp tác, các mối quan hệ công/ tư nhân, vốn xã hội.

- Các yếu tố (thực hiện/ triển khai) quá trình đổi mới nhu: số lượng các doanh nghiệp khởi tạo dựa trên đổi mới, các doanh nghiệp đồi mới đã thành lập hoặc doanh nghiệp khởi nghiệp, việc đổi mới thực hiện khả năng kết hợp các yêu cầu của khách hàng (hiện tại và tương lai) với các nguồn lực đổi mới có thể tiếp cận phát triển và khai thác. Quy trình thực hiện tổng thể bao gồm xác định thị trường, thiết kế, kỹ thuật, sản xuất, tiếp thị, phân phối và giai đoạn hỗ trợ. Những hoạt động này có thể được xem như là bước tuyến tính, nhưng thực tế trong nhiều trường hợp lại phi tuyến. Đối với mỗi giai đoạn của quy trình, có rất nhiều quy trình phụ. Một số vấn đề kinh tế và kỹ thuật trong quá trình phát triển thường tạo ra nhu cầu nghiên cứu bổ sung ngay cả đối với nghiên cứu cơ bản.

- Các yếu tố đầu ra đổi mới: yếu tố đổi mới giải quyết các kết quả đầu ra của hoạt động đổi mới. Đầu ra của đổi mới bao gồm các vấn đề đo lường phức tạp hơn và khó nắm bắt.

+ Các yếu tố tác động đến đầu ra của đổi mới: Sự phổ biến và áp dụng các sản phẩm, quy trình và dịch vụ mới tới khách hàng, doanh số, lợi nhuận bán hàng đóng góp từ các các sản phẩm, quy trình và dịch vụ mới, thay đổi về thị phần, doanh thu, thương hiệu và tài sản trí tuệ của doanh nghiệp

- Các yếu tố tác động kinh tế: đây là sự tác động qua lại giữa nền kinh tế với đổi mới doanh nghiệp và ngược lại khi năng suất lao động, thu nhập bình quân đầu người giảm, cạnh tranh kém, hàng hóa dịch vụ giảm dẫn đến GDP giảm do vậy doanh nghiệp cần phải đổi mới, khi có đổi mới dẫn đển tăng trưởng việc làm, năng suất, mức sống, khả năng cạnh tranh, thị phần do đó GDP tăng trưởng, lúc này GDP tăng thì có điều kiện tăng kinh phí đầu tư cho doanh nghiệp đổi mới.

\subsection{Các yếu tố môi trường}

- Điều kiện kinh tế vĩ mô: Các hoạt động sáng tạo của doanh nghiệp phụ thuộc phần lớn vào nhận thức của nền kinh tế quốc gia và toàn cầu nói chung và những kỳ vọng cho tương lai. Những rủi ro của đổi mới và những lợi ích dự kiến có liên quan đến điều kiện kinh tế vĩ mô trong nước và thị trường nước ngoài, chi phí vốn (lãi suất), xác định giá trị đồng tiền, và tiếp cận thị trường. Việc các doanh nghiệp nhận thức các điều kiện kinh tế vĩ mô như thế nào có thể thay đổi đáng kể tùy thuộc vào lĩnh vực công nghiệp, khu vực và công nghệ [5].

- Cơ sở ha tầng đổi mới: Cơ sở hạ tầng đổi mới của quốc gia giúp cung cấp đầu vào cho các doanh nghiệp tư nhân. Cơ sở hạ tầng này có thể được định hình đáng kể bởi các chính sách và đầu tư công bao gồm:

+ Cơ sở hạ tầng thông tin

+ Các cụm đổi mới

+ Các tổ chức khoa học và công nghệ

+ Các nhà cung cấp vốn và thị trường

+ Các cơ sở giáo dục

- Nhận thức của quốc gia: Thái độ của công chúng đối với khoa học, công nghệ và đổi mới và cách thức truyền tải thông tin liên quan đến đổi mới của các phương tiện truyền thông có thể ảnh hưởng đến các cuộc tranh luận chính trị, ảnh hưởng đển sự lựa chọn chính sách công, kích thích sự lựa chọn nghề nghiệp trong khoa 
học và kỹ thuật và thúc đẩy đầu tư công/ tư nhân trong hoạt động đổi mới.

- Môi truờng chính sách công: Khu vực công liên kết với quá trình đổi mới một cách mạnh mẽ và sâu sắc. Tài trợ $R \& D$ từ khu vực công chiếm một phần đáng kể trong đầu tư R\&D quốc gia. Các lựa chọn của chính phủ trong việc hỗ trợ một lĩnh vực khoa học (ví dụ, khoa học đời sống, công nghệ nano...) ảnh hưởng đến việc định hướng các hoạt động đổi mới sáng tạo. Tuy nhiên, $R \& D$ chỉ là một lĩnh vực chính sách công cộng có liên quan tới đổi mới.

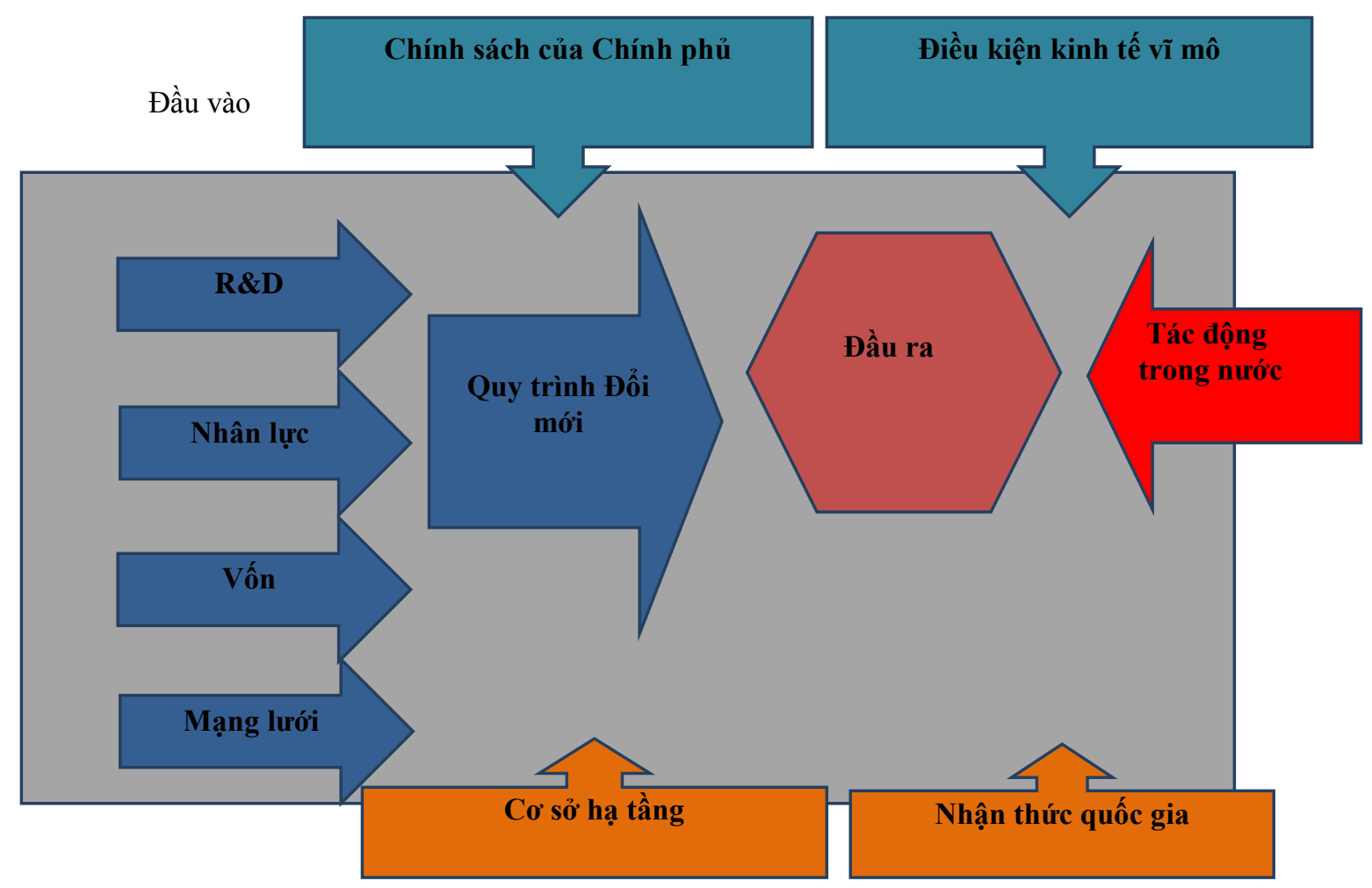

Hình 1. Sơ đồ các yếu tố tác động đến đổi mới của doanh nghiệp.

\section{Chính sách hỗ trợ doanh nghiệp đổi mới}

Trên cơ sở phân tích các yếu tố tác động đến đổi mới của doanh nghiệp tác giả xin đưa ra một số chính sách nhằm hồ trợ doanh nghiệp đổi mới góp phần nâng cao năng suất, chất lượng sản phẩm, hàng hóa góp phần tăng khả năng cạch trang của doanh nghiệp, đặc biệt là doanh nghiệp trong giai đoạn hội nhập hiện nay [6].

\subsection{Tài trọ cho $R-D$}

Hỗ trợ chính sách R-D có định hướng công nghệ cụ thể (ví dụ, công nghệ nano, công nghệ thông tin,...). Hỗ trợ cơ sở hạ tầng đổi mới của các trường đại học, trung tâm nghiên cứu, phòng thí nghiệm trọng điểm, chuyên ngành, khu vực... tập trung kinh phí thích đáng cho các chương trình quốc gia, hỗ trợ các doanh nghiệp khởi nghiệp, doanh nghiệp khoa học và công nghệ. Đơn giản hóa các thủ tục hành chính, quy trình khi thực hiện các nhiệm vụ R\&D.

\subsection{Huy động tài chính cho đổ mói doanh nghiệp}

Huy động nguồn kinh phí cho hoạt động đổi mới, theo nguyên tắc tỷ lệ kinh phí cho đổi mới phải tỷ lệ thuận với và tỷ lệ tăng trưởng kinh tế trong nước và giá trị thị trường chứng khoán của doanh nghiệp đồi mới... Chính sách tiền tệ, 
trong và ngoài nước, tác động tới cạnh tranh quốc tế.

\subsection{Chính sách chuyển giao công nghệ}

Hoàn thiện Luật chuyển giao công nghệ và các văn bản hướng dẫn phù hợp với thông lệ quốc tế, tạo điều kiện phát triển các liên kết hợp tác giữa ngành công nghiệp, doanh nghiệp trường đại học - phòng thí nghiệm

\subsection{Chính sách nguồn nhân lục}

các chương trình, các quỹ nghiên cứu đào tạo. Ưu đãi cung cấp lao động có trình độ cao cần thiết cho doanh nghiệp nghiên cứu khoa học, phát triển công nghệ và thương mại hóa công nghệ, sản phẩm.

\subsection{Chính sách thuế}

Hỗ trợ cung cấp các ưu đãi thuế cho các hoạt động nghiên cứu khoa học và triển khai công nghệ. Hỗ trợ giá cho các sản phẩm đổi mới.

\section{6. Áp dụng tiêu chuẩn quốc tế}

Đầu tư phát triển các tiêu chuẩn quốc tế và tạo điều kiện cho các doanh nghiệp áp dụng các tiêu chuẩn công nghệ nền tảng, chẳng hạn như Internet, hệ thống máy tính, phần mềm bởi vì các tiêu chuẩn cũng có chức năng như một rào cản phi thương mại đối với sự thay đổi về kỹ thuật và có thể hạn chế thị trường đặc biệt trong giai đoạn hội nhập quốc tế hiện nay.

\subsection{Chống độc quyền}

Khuyến khích hợp tác đổi mới ngành công nghiệp, doanh nghiệp. Khuyến khích gia nhập thị trường mới, cập nhật, tập trung vào các thị trường mới nồi toàn cầu và xây dựng chính sách chống độc quyền trong nước phát triển sản phẩm dựa trên nguyên tắc sản xuất - phân phối theo chuỗi cung ứng và cơ hội tác động đến các kết quả kinh tế mà không quan tâm tới biên giới quốc gia.

\subsection{Sở hũu trí tuệ}

Bảo vệ quyền lợi cho những tổ chức, cá nhân đăng ký sở hữu trí tuệ theo thông lệ quốc tế nhằm hạn chế sự xâm nhập của các đối thủ cạnh tranh.

\subsection{Tiếp cận thị truờng}

Tạo điều kiện cho các doanh nghiệp lựa chọn và tiếp cận thị trường nước ngoài, các điều kiện xuất, nhập khẩu đầu tư trực tiếp nước ngoài để phát triển thị trường ngoài nước.

\subsection{Quy định kinh tế}

Kiểm soát các chính sách tác động đến đầu tư đổi mới thông qua kiểm soát giá, tỷ suất lợi nhuận, hạn chế cổ phiếu thị trường, và sự xuất hiện của các lựa chọn thay thế cạnh tranh.

\subsection{Quy định về môi trường và xã hội}

Xây dựng quy định về môi trường và xã hội để kích thích sự sáng tạo của các cá nhân, tổ chức tham gia vào hoạt động của đổi mới để góp phần tạo điều kiện cho mối quan hệ giữa ngành công nghiệp, doanh nghiệp với các nhà cung cấp.

\subsection{Chính sách chăm sóc súc khỏe}

Chính sách phát triển, nâng cao sức khỏe con người và nhu cầu chăm sóc sức khỏe tạo ra cơ hội cho các sản phẩm, dịch vụ mới và các công nghệ nâng cao năng suất có khả năng tác động đáng kể trong việc chăm sóc và điều trị bệnh, cũng như trong việc phòng, tránh bệnh tật.

\subsection{Chính sách bảo mật}

Có chính sách bảo mật, an toàn thông tin cho doanh nghiệp về hồ sơ cá nhân, các mối đe dọa tới việc truy cập tới dữ liệu của tội phạm và khả năng sử dụng gian lận hồ sơ bí mật cá nhân.

\subsection{Chính sách An ninh}

Tạo ra môi trường đổi mới thuận lợi và an toàn cho doanh nghiệp và tạo ra các yêu cầu kinh tế bổ sung cho việc quản lý rủi ro và các lỗ hổng của hầu hết các ngành kinh tế, trong đó có ngành công nghệ thông tin, ngành tài chính, 
nước, năng lượng, giao thông vận tải, chuỗi cung ứng sản xuất...

\section{Tài liệu tham khảo}

[1] Joseph A. Schumpeter, Theory of Economic Development, Transaction Publishers, 1934.

[2] Oslo Manual, Guidelines for Collecting and Interpreting Innovation Data, Organization for Economic Co-operation and Development (OECD) and Statistical Office of the European Communities (Eurostat), Paris, 2005.

[3] Quốc hội, Luật Khoa học và Công nghệ, Điều 3, khoản 16, Hà Nội, 2013
Office of the European Communities, Eurostat.). (OECD / EUROSTAT, 2005)

[4] Phạm Thế Dũng, Điều tra đổi mới công nghệ, kinh nghiệm quốc tế và định hướng áp dụng cho Việt Nam, Khoa học và công nghệ, Công thương 22 (2015), 26.

[5] Phạm Thế Dũng, Mô hình đánh giá đổi mới công nghệ, Hội thảo khoa học 08/07/2015, Hà Nội, 2015.

[6] Phạm Thế Dũng, Chính sách hỗ trợ đổi mới công nghệ cho doanh nghiệp Việt Nam, Hội thảo Hỗ trợ đổi mới công nghệ cho doanh nghiệp vùng Đồng Bằng sông Cửu Long đáp ứng yêu cầu hội nhập TPP, 4/2016.

\title{
Policy for Supporting Enterprises Innovation
}

\author{
Pham The Dung ${ }^{1}$, Nguyen Dinh Duc ${ }^{2}$ \\ ${ }^{1}$ Ministry of Science and Tecnology, 113 Tran Duy Hung, Hanoi, Vietnam \\ ${ }^{2}$ Vietnam Nation University, Hanoi, 144 Xuan Thuy, Hanoi, Vietnam
}

\begin{abstract}
Innovation in enterprises plays a very important role in creating new products, improving labor productivity and product quality, rationally using and saving materials, increasing competitiveness and expanding markets, protecting the environment, improving living conditions, limiting the influence of nature on production and life, especially in the period of industrialization and modernization, in the condition of market economy and international integration. Therefore, it is necessary to develop a policy to support enterprises in order to meet the requirements of integration as well as create a favorable legal environment to promote innovation in enterprises.
\end{abstract}

Keywords: Inovation in enterprises. 